\title{
Remuneração Variável de Professores: controle, culpa e subjetivação
}

\begin{abstract}
Simone Torres Evangelista' Igor Vinicius Lima Valentim"

'Universidade Federal Fluminense (UFF), Niterói/RJ - Brasil "Universidade Federal do Rio de Janeiro (UFRJ), Rio de Janeiro/RJ - Brasil

RESUMO - Remuneração Variável de Professores: controle, culpa e subjetivação. A cada dia fica mais difícil distinguir a administração pública da privada. Valores capitalistas são naturalizados para todas as esferas da vida humana. Modelos e políticas da gestão de empresas voltadas para o lucro têm sido cada vez mais importados para a administração pública brasileira principalmente a partir de 1995, com a Reforma Gerencial do Estado. No rastro dessas importações, diversos estados e municípios brasileiros já utilizam a remuneração variável por desempenho para gerir professores. Em que medida a remuneração variável por desempenho, aplicada a professores, pode construir novas subjetividades, funcionando como instrumento de controle e de culpabilização desses mesmos docentes? Esta é a indagação que norteia este artigo.

Palavras-chave: Subjetivação. Controle. Culpa. Remuneração Variável. Trabalho Docente.
\end{abstract}

ABSTRACT - Teachers' Variable Payment: control, guilt and subjectivation. Each day it becomes more difficult to distinguish between public and private administration. Capitalist values are naturalized to all spheres of human life. Models and policies of the management of companies focused on profit have been progressively more imported to Brazilian public administration, mainly after 1995, with the management reform of the State. Several municipalities and states already use variable payment systems based on performance to manage teachers. To what extent variable payment by performance, applied to teachers, may build new subjectivities, functioning as an instrument of control and guilt of these teachers? This is the question that guides this paper.

Keywords: Subjectivation. Control. Guilt. Variable Payment. Teachers' Work.

Educação \& Realidade, Porto Alegre, v. 38, n. 3, p. 999-1018, jul./set. 2013.

Disponível em: <http://www.ufrgs.br/edu_realidade> 


\section{Introdução}

Desde a década de 1970, o neoliberalismo, cujos objetivos vão na direção de ter o mercado e os interesses empresariais como norteadores das sociedades através da redução do papel do Estado na economia, tem sido tratado por muitos como uma tábua de salvação para diversas crises enfrentadas. Foram se intensificando mudanças que acarretaram reconfigurações políticas, sociais e econômicas em escala mundial.

A administração pública, tradicionalmente encarada como representante de interesses diferentes da administração privada, não ficou de fora dessas mudanças. Estratégias e políticas empresariais baseadas na competição e em uma suposta excelência, provenientes da administração de organizações privadas, têm sido progressivamente importadas para a gestão pública.

Constroem-se Estados baseados em políticas, técnicas e ferramentas de formas de administrar que ganham corpo em uma Administração desenvolvida como ciência, no mesmo ritmo em que se importam, com essas políticas, princípios e valores capitalistas. Entretanto, pouco se discute que esta Administração sempre esteve voltada exclusivamente para o lucro.

No Brasil, essa forte tendência de importação de modelos administrativos estrangeiros para o setor público ganhou mais corpo a partir de 1995, com a Reforma Gerencial do Estado (Brasil, 1995; Bresser Pereira, 2000), cujo objetivo, ao menos no discurso oficial, era a melhoria da eficiência e da eficácia do serviço público. Isto seria obtido através de um novo modelo de gestão que primasse pela competição administrada, pela excelência e pelo controle social.

Eficiência, eficácia, competição administrada, controle social, excelência. Estes eram alguns dos valores estimulados pela mencionada reforma. A chamada nova gestão pública também atingiu a esfera educacional. As mudanças na política educacional brasileira passaram a ser pautadas pela busca de uma pedagogia de resultados, que seguia a lógica do controle do trabalho (Ball, 2001).

Dentro do setor governamental e mais especificamente na área da Educação, esse novo gerencialismo passou a modificar seriamente as próprias políticas de gestão do trabalho docente. No seio da política educacional brasileira, essas mudanças ganharam força com o Plano de Desenvolvimento da Educação (PDE) (Brasil, 2007), que condicionou o apoio técnico e financeiro do Ministério da Educação ao Índice de Desenvolvimento da Educação Básica (IDEB).

Eis que o governo passa a monitorar a suposta qualidade educacional através de avaliações realizadas em larga escala. Estados e municípios são induzidos a aderirem às diretrizes propostas pelo Governo Federal, já que este passa a atrelar apoio técnico e financeiro ao acompanhamento e melhoria de índices parametrizados de avaliação, tais como o IDEB.

1000 Educação \& Realidade, Porto Alegre, v. 38, n. 3, p. 999-1018, jul./set. 2013. Disponível em: <http://www.ufrgs.br/edu_realidade> 
Índices e rankings passam a fazer parte do cotidiano da educação e paulatinamente são aceitos por muitos como sinônimos de bons indicadores para avaliar a qualidade da educação. Na medida em que esses índices são naturalizados como fiéis da balança da qualidade educacional, por que não atrelar parte dos salários dos professores a eles?

A política de remuneração docente não esteve imune a mudanças ao longo do tempo e já foi tema de diversos estudos que abordam inclusive a progressiva precarização dos salários e do trabalho docente (Codo, 1999; Oliveira, 2004; Costa, 2009). Entretanto, as novidades que aqui focamos são aquelas relacionadas à remuneração variável por desempenho aplicada ao trabalho docente, que vinculam parte do salário de professores a resultados obtidos pelos alunos e pelas escolas.

Da mesma forma que vendedores recebem comissões de acordo com suas vendas, diversas redes de ensino ao redor do Brasil (e do mundo) passam a progressivamente atrelar prêmios, bônus e afins, ou seja, partes da remuneração docente, às notas de alunos, turmas, unidades escolares, regiões administrativas e redes educacionais. Isto parece representar uma mudança significativa para o trabalho (e para a vida) docente, impactando a prática destes profissionais, que até então recebiam remunerações fixas, independente de qualquer aspecto ligado à sua produtividade.

Pesquisas têm sido feitas (Cassetari, 2010; Rodrigues, 2010) sobre este tema, mas ainda são muitas as lacunas. Em que medida a remuneração variável por desempenho dos professores pode construir novas subjetividades, funcionando como instrumento de controle (Foucault, 2005) e de culpabilização desses mesmos docentes? Esta é a indagação que norteia este artigo.

O presente texto se inicia com uma contextualização a respeito de alguns modelos administrativos e valores subjacentes a eles. A seguir, realizamos breve discussão acerca das mudanças ocorridas a partir da importação desses modelos para o contexto da gestão pública, passeando pela Reforma Gerencial do Estado de 1995 e pelo que diz respeito às políticas públicas na área da Educação.

Em seguida, a partir de políticas concretas desenvolvidas no Brasil, abordamos a recente introdução da remuneração variável por desempenho em algumas prefeituras e estados, para então analisarmos em que medida esse novo modelo de gestão da remuneração docente pode estimular sentimentos tais como o de culpa e o controle dos docentes, construindo novas subjetividades. Refletimos, finalmente, em que medida as políticas instituídas podem acabar por cumprir um papel que se estenda para além do controle do trabalho docente, ultrapassando os muros das escolas, e sejam compreendidas como instrumentos de gestão não apenas do trabalho, mas da própria vida desses professores e professoras, para além de estimularem a reprodução de valores da lógica capitalista, hoje dominante.

Educação \& Realidade, Porto Alegre, v. 38, n. 3, p. 999-1018, jul./set. 2013. 1001 Disponível em: <http://www.ufrgs.br/edu_realidade> 


\title{
Alguns Modelos Administrativos e seus Valores
}

A administração pública sofreu uma avalanche de mudanças através da importação de políticas e estratégias organizacionais oriundas de modelos administrativos criados para a gestão de empresas privadas voltadas para o lucro como objetivo maior. Dentre alguns dos modelos administrativos que serviram de base para este fenômeno encontramse o Taylorismo (Taylor, 1990), o Fordismo (Ford, 1964) e o Toyotismo (Ohno, 1997).

No final do século XIX, as indústrias dos EUA encontravam dificuldades para enfrentar a concorrência de outras no mercado, tanto devido à forma de conduzir o negócio, quanto à maneira de gerir o trabalho operário. Apesar de o racionalismo científico ter alcançado seu ápice no século XVIII, ele ainda não havia afetado o campo do trabalho, ou seja, “[...] ainda não havia provocado a racionalização da organização e execução do trabalho” (Motta e Vasconcelos, 2006. p. 24).

Já no século XX, em 1911, Frederick Winslow Taylor, no ímpeto de atender às necessidades de eficiência industrial, publicou seu livro Princípios da Administração Científica e um estudo da administração como ciência. Ele (Taylor, 1990, p. 23) dizia que “[...] o remédio para a ineficiência está antes na administração que na procura do homem excepcional ou extraordinário”. Taylor preocupou-se com a racionalização dos custos, com a intenção de obter o máximo de rendimento e eficiência com o mínimo de tempo e atividade, ou seja, produzir mais com menos. Ele pensou em um método rígido e padronizado que contemplasse o monitoramento da produção e o controle do ritmo de trabalho. Para isso, utilizou-se de supervisão humana para monitorar os operários e diminuir o que chamava de vadiagem, bem como dividiu o trabalho (treinando e especializando o operário numa única tarefa) e implementou uma hierarquia administrativa com a criação das funções de diretor, gerente e administrador. Para ele,

\begin{abstract}
[...] o trabalhador, ainda que bem habilitado na organização e uso dos dados científicos, estaria materialmente impossibilitado de trabalhar, ao mesmo tempo, na máquina e na mesa de planejamento. Está claro, então, na maioria dos casos, que um tipo de homem é necessário para planejar e outro diferente para executar o trabalho (Taylor, 1990, p. 41).
\end{abstract}

No que diz respeito à remuneração do trabalhador, Taylor utilizou a estratégia de pagamento por peça, que consistia em treinar o indivíduo para a execução de uma tarefa específica, de forma mais rápida e melhor, pagando-lhe de acordo com sua produtividade.

A Administração Científica de Taylor possuía uma racionalidade absoluta que tratava os incentivos monetários como indutores de comportamentos (Motta e Vasconcelos, 2006). Como ele mesmo afirmava, “[...] a ambição pessoal sempre tem sido, e continuará a ser, um incen- 
tivo consideravelmente mais poderoso do que o desejo do bem-estar social" (Taylor, 1990, p. 73).

O sistema taylorista gerou a propagação do trabalho assalariado, mas também a exploração e o disciplinamento (Foucault, 2005) do trabalhador. As condições de trabalho eram péssimas e a atividade desempenhada dentro das fábricas era majoritariamente mecânica: ao operário só cabia a execução. Havia um capataz vigiando para que as máquinas não parassem (Dejours, 1992).

A disciplina poderia ser considerada como chave para obtenção do fim maior dessas indústrias, o lucro, e o trabalhador era mero instrumento, recurso humano cujo comportamento precisava ser moldado por meio de uma remuneração realizada de acordo com sua produtividade.

Em 1914, Henry Ford introduziu um modelo de gestão pautado em uma linha de montagem, que substituía a produção por peça do modelo taylorista pela produção e gestão em massa. O modelo fordista não substituiu a Administração Científica de Taylor, mas conservou muitas de suas práticas, representando um avanço tecnológico. Ford expressou isso ao dizer que pensava "[...] numa melhor organização e em um melhor ajustamento" (Ford, 1964, p. 12).

O modelo fordista manteve o mesmo princípio rígido de especialização do trabalho e racionalização do tempo em função do aumento da produtividade. Henry Ford, assim como Taylor, também considerava que o modo de gestão precisava ser um poderoso fator de disciplinamento (Foucault, 2005) dos trabalhadores. Ele atrelou o aumento de salário como indutor comportamental, com o objetivo final do crescimento da produção e é possível perceber, em suas palavras, que o trabalhador deveria receber de acordo com o que produzisse:

\begin{abstract}
Exigimos que os operários executem o que se lhes ordena. Nossa organização é tão especializada, e tão intimamente se relacionam as partes, que nem por um momento poderíamos deixar ao operário liberdade de ação. Sem disciplina severa haveria uma confusão espantosa. Uma empresa industrial não pode comportar-se de outro modo. É preciso que os homens realizem um máximo de trabalho para terem um máximo de salário. Se a cada um se deixasse fazer como bem entende, a produção se ressentiria e com ela o salário. Quem não está contente não é obrigado a ficar (Ford, 1964, p. 85).
\end{abstract}

Outra preocupação de Ford era quanto ao absenteísmo, combatido firmemente por ele:

Nos casos de ausência é necessário usar de rigor. Os operários não podem entrar e sair a seu bel-prazer; é de obrigação pedir licença ao chefe, e caso alguém se ausente sem autorização prévia, examinam-se as suas razões, algumas vezes fazendo-o passar pelo gabinete médico.

Educação \& Realidade, Porto Alegre, v. 38, n. 3, p. 999-1018, jul./set. 2013.1003 Disponível em: <http://www.ufrgs.br/edu_realidade> 
Quando as circunstâncias lhe são favoráveis volta para o trabalho. Em caso contrário é despedido (Ford, 1964, p. 86).

É possível perceber que tanto o fordismo quanto o taylorismo atrelavam a remuneração dos trabalhadores à sua produtividade, bem como promoviam um rígido controle das suas vidas. Este controle ia muito além dos muros das fábricas: “[...] no tempo em que aumentamos os salários, também aumentamos de vigilância, e averiguamos da vida particular de cada um, para saber o destino que davam aos seus salários" (Ford, 1964, p. 186).

Não é difícil inferir que as relações de trabalho tiveram conexão com os modos de produção e gestão e, com o passar do tempo, surgiram novas preocupações dos administradores, buscando soluções para problemas trabalhistas sem o uso da força ou coerção física dos trabalhadores. Entretanto, é importante ressaltar que, no contexto das organizações, cada vez mais o lucro se reafirmou como objetivo maior, servindo de causa máxima para quaisquer mudanças dentro das políticas de gestão do trabalho e da vida humana.

Na década de 1970, o mundo viu-se envolvido em transformações econômicas, principalmente com a crise do petróleo. Neste período de grande crise da acumulação capitalista, as ideias neoliberais foram ganhando cada vez mais terreno. Foi preciso quase uma década para que o programa neoliberal chegasse ao seu ápice na Inglaterra de Margareth Thatcher, embora também tivesse ganhado força na Europa e na América do Norte de Ronald Reagan, que não conseguiu respeitar a disciplina orçamentária recomendada pelo programa neoliberal devido aos gastos bélicos.

Nessa mesma época, o Japão estava em evidência no contexto capitalista e já vinha desenvolvendo desde o pós-guerra um novo modo de gestão da produção, elaborado por engenheiros da Toyota e sistematizado por Taiichi Ohno (1997), que originou o livro intitulado O Sistema Toyotista de Produção em larga escala. O toyotismo dissemina e engloba técnicas de administração flexível do capital e se baseia na flexibilização de máquinas, ferramentas e também do trabalho humano, substituindo a rigidez do modelo Fordista de produção. Ohno (1997, p. 28) observa que

[...] o Sistema Toyota de Produção, com seus dois pilares defendendo a absoluta eliminação do desperdício, surgiu no Japão por necessidade. Hoje, numa época de lento crescimento no mundo inteiro, esse sistema de produção representa um conceito em administração que funcionará para qualquer tipo de negócio.

O toyotismo mantém a mesma lógica de racionalização dos gastos que o fordismo e o taylorismo, porém, provoca "[...] mudanças institucionais e organizacionais nas relações de produção" (Laranjeira, 1997, 
p. 77). Assim como o taylorismo e o fordismo, o toyotismo buscou construir "[...] uma nova hegemonia capaz de articular coerção capitalista e consentimento do trabalhador [...] por meio de mecanismos de envolvimento estimulado do trabalho vivo" (Alves, 2011, p. 99-100).

O Sistema Toyota de Produção provocou uma transformação ético-moral das relações interpessoais já que, ao mesmo tempo em que promove o trabalho em equipe, faz uso da administração por estresse, ou seja, utiliza-se de técnicas em que um trabalhador controla a qualidade do exercício laboral do outro. A queda de produção de um gera queda de produção do grupo e, consequentemente, problemas para a coletividade. Aquele que deixa de produzir por algum motivo tende a ser rejeitado pelo grupo (Alves, 2011).

O controle passa a ser exercido não apenas por um superior hierárquico, como no taylorismo e no fordismo, mas agora também entre os próprios colegas de trabalho de mesmo nível hierárquico e pela própria pessoa sobre si mesma: autocontrole. Convivência de aspectos de uma sociedade disciplinar (Foucault, 2005) com traços de uma sociedade de controle (Deleuze, 1992).

A gestão participativa proposta pelo toyotismo busca premiar os trabalhadores que aderem e alcançam as metas da empresa, porém, ao mesmo tempo, estimula a competição entre os funcionários na busca por um suposto reconhecimento do trabalho produzido por cada um. Ao oferecer incentivos financeiros como prêmios, bônus ou gratificações por desempenho, a empresa acaba por convencer e, porque não dizer disciplinar seus funcionários, em torno de uma busca incessante dos objetivos da empresa, que passam a ser seus também.

Nessa busca, uma competição é instaurada na instituição e acaba por corromper as relações e as noções de ética, companheirismo, cooperação acabam sendo suplantadas. Esses são alguns dos valores estimulados pelo toyotismo e construídos no cotidiano dentre deste modelo de trabalho. Valores que não se limitam aos muros das empresas, mas que buscam ser inscritos no comportamento de todos os funcionários. A título de exemplo, basta lembrar que o Toyotismo (Ohno, 1997) estimula o perfeccionismo como valor.

Desta forma, é possível entender porque, para Lazzarato (2006), o capitalismo assume um aspecto cognitivo, na medida em que não é mais apenas um modo de produção, mas uma produção de modos de existência, de sentidos, de subjetividades. No capitalismo contemporâneo a subjetividade é um tema central, já que a produção essencial desta lógica diz respeito aos comportamentos, à nossa percepção, sensibilidade, às relações sociais, aos fantasmas imaginários, entre outros tantos aspectos. Nesse sentido, a produção de bens e mercadorias tem um papel complementar ao principal cerne do capitalismo, constituído pela gestão das formas atuais e potenciais de vida humana em suas diferentes esferas.

Educação \& Realidade, Porto Alegre, v. 38, n. 3, p. 999-1018, jul./set. 2013. 
Mas como ocorrem os processos de produção de subjetividade ou de subjetivação? Entendemos que o sujeito não é algo que encontramos pronto, como um dejá-là, algo do domínio de uma suposta natureza humana. Ao contrário disso, consideramos, na mesma linha de Guattari e Rolnik (2007), que a subjetividade tem natureza maquínica, ou seja, ela é fabricada, modelada, recebida, consumida.

Gilles Deleuze (1992, p. 142) coloca o tema de forma brilhante quando afirma que "[...] a subjetivação é a produção dos modos de existência ou estilos de vida”. Portanto, as políticas de subjetivação são constituídas nas diversas formas por meio das quais os sujeitos se constroem e são construídos a partir de suas experiências de vida (Nardi, 2006). Em cada contexto espacial, social e temporal, os diversos significados atribuídos à existência adquirem sentido dentro de um jogo de verdades próprio.

Concordamos com Suely Rolnik (2006) quando ela afirma que políticas de subjetivação mudam de acordo com os regimes, já que eles dependem da construção de subjetividade para serem viabilizados, ganharem consistência e concretude no cotidiano de todos, de cada um.

Os modelos administrativos podem ser considerados, portanto, roupagens bonitas, ou seja, instrumentos que visam à construção e naturalização de valores, comportamentos, modos de sentir e viver: políticas de subjetivação.

Relações familiares, profissionais, amorosas e para com todo o ambiente do qual somos parte são cada vez mais perpassadas por valores como os citados acima. Não obstante, eficiência, eficácia e competência são termos cada vez mais frequentes em todas essas relações, embora importados da gestão de empresas privadas voltadas para o lucro: cada um de nós vive e constrói a lógica capitalista.

Valores como a competição, o individualismo, a crença no progresso como solução para todos os problemas e uma maior preocupação com os fins do que com os meios utilizados para se chegar até eles têm se expandido e se naturalizado para todas as dimensões da vida, mesmo dentro da esfera governamental.

\section{Importação de Valores Capitalistas para o Setor Público e para a Esfera Educacional}

No Brasil, a importação dos modelos e, principalmente, dos valores administrativos (capitalistas) para o setor público acirrou-se a partir de 1995, com a Reforma Gerencial do Estado (Brasil, 1995). De acordo com Bresser Pereira (2000), um dos focos da reforma foi a melhora da eficiência no serviço público, adotando-se um novo modelo de gestão chamado de Administração Gerencial.

A mencionada reforma, inspirada grandemente no modelo neoliberal de Thatcher e Reagan previa, dentre outros aspectos, uma ad- 
ministração voltada para um novo modelo de responsabilização de gestores, visando à administração por resultados, à competição administrada por excelência e ao controle social. Pouco se discutiu, no seio da sociedade, a respeito dos objetivos governamentais e buscaram-se naturalizar vários dos valores e princípios administrativos capitalistas. Esqueceu-se de mencionar que se estava acelerando a importação, para a administração de um país, de princípios criados no âmbito de empresas privadas voltadas exclusivamente para o lucro.

As mudanças na gestão pública também atingiram a esfera educacional. Dentro da ofensiva neoliberal, a educação começou a ser vista como um serviço que "[...] tem que ser oferecido ao mercado com qualidade e deve ser produtivo e competitivo” (Costa et al., 2009, p. 30). Em outras palavras, introduziu-se a mercantilização dos serviços públicos sob o discurso sedutor de que a mudança se fazia necessária em prol do desenvolvimento, da modernização e do suposto bem social.

Em um modelo de administração pública que incorporava cada vez mais aspectos da gestão privada, as atenções também se voltaram para a gestão dos recursos humanos, introduzindo técnicas mais elaboradas de motivação e envolvimento dos trabalhadores na busca pela suposta qualidade e produtividade. No seio da política educacional brasileira, essas mudanças ganharam força com o Plano de Desenvolvimento da Educação (PDE) (Brasil, 2007), que condicionou o apoio técnico e financeiro do Ministério da Educação ao IDEB (Índice de Desenvolvimento da Educação Básica).

O IDEB é calculado com base nas taxas de aprovação e nos resultados de proficiência auferidos por cada município e escola pública do país, e foi criado para servir de base para parte dos repasses federais às prefeituras, na área de educação. O governo fixou metas para, ao fim e ao cabo, condicionar a liberação dos recursos à melhoria do novo índice municipal de educação.

A metodologia do IDEB, em termos resumidos, é a seguinte: multiplica-se a taxa média de aprovação de uma etapa escolar específica, pela nota padronizada nos testes de Matemática e Português do SAEB, ou Prova Brasil. A simples multiplicação dos dois termos dá o valor do IDEB. Este mecanismo de avaliação enfatiza aspectos quantificáveis, mensuráveis, em detrimento dos aspectos qualitativos que envolvem os processos educacionais.

Cada escola (e cada rede pública de ensino) passou a ter um número, um índice como meta, uma nota como objetivo maior de seu funcionamento. Uma das características do IDEB é que ele suscitou a conversão de aspectos humanos em dados, na linha do que Foucault (2008, p. 389) argumentou sobre o uso da estatística e da racionalidade econômica como "[...] ciência do governo [...]" que busca administrar, aperfeiçoar e produzir novas consciências individuais e coletivas.

Não é difícil perceber que as mudanças na política educacional do Brasil foram se pautando cada vez mais em uma pedagogia de resul-

Educação \& Realidade, Porto Alegre, v. 38, n. 3, p. 999-1018, jul./set. 2013. 1007

Disponível em: <http://www.ufrgs.br/edu_realidade> 
tados (Ball, 2001), que tem como base, entre outras, a lógica do controle do desempenho da força de trabalho docente inspirada no programa de qualidade total e produtividade.

Seguindo a importação dos valores e ferramentas administrativos neoliberais para a política educacional brasileira, como que em um efeito cascata, redes de ensino das esferas municipal e estadual passaram a ter a incumbência de motivar seus professores e gestores para o alcance das metas estabelecidas para as instituições escolares às quais estão vinculadas. Construiu-se, então, o uso da remuneração variável por desempenho ou, como é mais conhecida no campo educacional, o prêmio por desempenho.

\section{A Remuneração Variável por Desempenho na Educação Brasileira: subjetivação}

O discurso que acompanha a utilização da remuneração variável por desempenho (Mello, 1994; Robbins, 2002) e, de maneira mais ampla, da gestão por desempenho, busca introjetar nos professores certa identificação com a organização à qual pertencem. Muitas vezes, nesses casos, os profissionais naturalizam os valores e tomam como seus os objetivos organizacionais: construção de subjetividades.

A consciência das forças que atravessam o campo das relações de trabalho pode ser determinante para a aceitação dos critérios impostos para o alcance do prêmio. Tudo dependerá da forma como as subjetividades são construídas. Quanto a isso, Deleuze (1992, p. 221) observa que os controles são uma modulação, como uma moldagem autodeformante que muda continuamente, a cada instante. Isto se vê claramente na questão dos salários. Ele afirma que “[...] o princípio modulador do 'salário por mérito’ tenta a própria Educação nacional”, na medida em que provoca a competição e a rivalidade entre os indivíduos, atravessando cada um e dividindo-os em suas convicções.

A Administração como ciência parece se vestir e revestir de modismos, nomes pomposos e novos para buscar mais do mesmo: o lucro acima de qualquer coisa. E, assim como o taylorismo, o fordismo e o toyotismo, é possível perceber que a gestão por desempenho também representa mais que um controle do trabalho, possuindo aspectos políticos, cognitivos e afetivos.

Pelo que já abordamos a respeito de modelos de gestão aqui neste texto, é possível perceber que os preceitos de remunerar o trabalho humano por desempenho e/ou por produtividade não são novos. A novidade parece residir justamente na aplicação desse tipo de remuneração (e de gestão) ao trabalho docente.

É importante ressaltar que o controle potencializado pelo IDEB se intensifica ainda mais quando o governo opta por divulgar os resultados obtidos pelas unidades escolares no índice, classificando-as, cons- 
truindo um ranqueamento e proporcionando a busca desenfreada por mecanismos que promovam a melhoria dos resultados por parte das redes de ensino, apenas para citar alguns dos efeitos mais visíveis.

A nova política insere na educação o que Lyotard (2011) chama de performatividade como sistema de terror, em um governo que regula e controla de forma invisível, que expõe as escolas, comparando-as através da divulgação de um ranking e transferindo a responsabilidade pelo fracasso/sucesso escolar para professores e alunos. É o que aponta Ball:

A performatividade desempenha um papel crucial nesse conjunto de políticas. Ela permite que o Estado se insira profundamente nas culturas, práticas e subjetividades das instituições do setor público e de seus trabalhadores, sem parecer fazê-lo. Ela (performatividade) muda o que ele 'indica', muda significados, produz novos perfis e garante o 'alinhamento'. Ela objetifica e mercantiliza o trabalho do setor público, e o trabalho com conhecimento (knowledge-work) das instituições educativas transforma-se em 'resultados', 'níveis de desempenho', 'formas de qualidade'. Os discursos da responsabilidade (accountability), da melhoria, da qualidade e da eficiência que circundam e acompanham essas objetivações tornam as práticas existentes frágeis e indefensáveis - a mudança torna-se inevitável e irresistível, mais particularmente quando os incentivos estão vinculados às medidas de desempenho (Ball, 2004, p. 1116).

A performatividade está profundamente relacionada à subjetividade quando cria índices de qualidade que medem um suposto mérito docente. A ansiedade gerada na longa espera pela divulgação do resultado das metas, bem como as consequências que isso traz, pode engendrar sentimentos como culpa orgulho, competição, vergonha e inveja.

Stephen Ball complementa afirmando que

[...] o que está em jogo não é a possível certeza de ser vigiado, e sim, a incerteza e a instabilidade de estar sendo avaliado de diferentes maneiras, por diferentes meios e por distintos agentes; é o 'surgimento' do desempenho, da performance- o fluxo de exigências que mudam, expectativas e indicadores que nos fazem continuamente responsabilizados e constantemente vigiados (Ball, 2001, p. 110).

Junto ao “[...] salário por mérito [...]" (Deleuze, 1992, p. 221-222), outros mecanismos de moldagem do trabalho (e da subjetividade) docente são utilizados pela gestão pública, de modo a motivar uma maior produtividade. Muitas redes de ensino no Brasil se utilizam da estratégia do prêmio por desempenho, atrelando-lhe condicionantes como a frequência ao trabalho. Dessa forma, o docente, além de buscar incondicionalmente a melhora do índice de desempenho, precisa manter sua frequência integral de modo a fazer jus ao recebimento do prêmio.

Educação \& Realidade, Porto Alegre, v. 38, n. 3, p. 999-1018, jul./set. 2013. 
Em algumas redes de ensino, tais como no município do Rio de Janeiro, a exigência de frequência integral é tão extremada que são impostos limites de afastamentos do trabalho ao professor, mesmo quando estes se dão por motivos médicos. No caso desta rede de ensino, aqueles que faltarem ao trabalho, mesmo por motivos médicos (Rio de Janeiro, 2009), acima do limite permitido, estarão excluídos da possibilidade de vir a receber o prêmio. Isso é tratado como se fosse uma questão de meritocracia ${ }^{1}$. Quem não age como o sistema espera ou questiona-o, é punido. Esse é um mecanismo de controle que tem a intenção de construir comportamentos:

Quem exercer o 'direito' de ficar doente poderá fazê-lo, mas não impunemente: todas as faltas e licenças de toda natureza e até licença-prêmio- concessão de três meses de afastamento remunerado do trabalho para quem for frequente ao longo de cinco anos - são descontadas do bônus-resultado (Costa et al., 2009, p. 122).

O prêmio/bonificação mascara as reais intenções administrativas que devem fazer os indivíduos quererem o que o sistema precisa para que opere satisfatoriamente (Lyotard, 2011). O próprio professor se culpa. É a produção de professores dóceis. O que temos é uma camuflagem dos discursos que trazem em seu âmago a intenção de disciplinar e controlar. Discursos que clamam pela coletividade, mas que incentivam a individualização. Moreira nos alerta que

[...] a individualização tornou-se uma fatalidade, não se trata mais de uma escolha do indivíduo a opção de escapar e se recusar a participar do jogo. Até mesmo adoecer não pode mais ser atribuído à fatalidade e sim ao comportamento inadequado do sujeito em relação a sua saúde e seu próprio corpo, o insucesso é atribuído a cada um, é sua responsabilidade [...]. A individualização remete a que o indivíduo sonhe só e projete sua vida independentemente e apesar do outro. Refere-se a um tipo de libertação das pessoas para torná-las indiferentes aos demais, não se reconhecendo como parte de algo maior (Moreira, 2007, p. 99-100).

Essa política de gestão do trabalho docente pode também modificar o modo como o professor vê os seus pares, sabotando as relações interpessoais e incentivando a competição interna do grupo, onde um começa a controlar o outro, tanto no sentido da produtividade quanto no sentido do absenteísmo. Se alguém falha ou falta, a produtividade cai e a coletividade perde o prêmio. Tudo o que possa representar queda na produtividade é passível de pressão coletiva. Nesse sentido as relações se tornam minadas e valores como companheirismo, confiança, solidariedade e ética profissionais se veem ameaçados pela sedução do prêmio. Muitas vezes, por medo da pressão ou por necessidade financeira, o professor pode acabar renunciando até mesmo a direitos como licenças para tratamento de saúde.

1010 Educação \& Realidade, Porto Alegre, v. 38, n. 3, p. 999-1018, jul./set. 2013 Disponível em: <http://www.ufrgs.br/edu_realidade> 
A remuneração por desempenho aplicada ao trabalho docente é um acontecimento singular que representa a corrupção da educação que se vende ou negocia em troca do dinheiro. Dizemos acontecimento concordando com o conceito de Foucault (2002), que proclama o acontecimento como uma potência que perturba a nossa compreensão de mundo e do que somos. Remunerar por desempenho cria novas subjetividades ao modificar o modo como o indivíduo vê a si, ao seu trabalho e aos outros.

A maior parte das redes municipais e estaduais estimula, no discurso oficial, a qualificação de seus professores. Entretanto, na prática, este estímulo parece ocorrer apenas em cursos à distância (que podem ser realizados à noite, de madrugada e em fins de semana) e fora do horário de trabalho (como aos sábados, por exemplo). Nesse sentido, caminha-se na direção que os docentes busquem aperfeiçoamento contínuo e qualificação, desde que isso aconteça fora do horário de trabalho regular. Mas, então, que estímulo é esse? A que continuem trabalhando mesmo fora do horário?

É possível perceber que embora o discurso oficial estimule a qualificação, a continuidade dos estudos em cursos de Especialização, Mestrado e Doutorado, para os docentes que já possuem a Graduação, pode também representar problemas na ótica dos colegas de unidade escolar quando há controle mútuo em prol do resultado nas avaliações parametrizadas: todo o resto vira supérfluo e pode até mesmo atrapalhar o atingir das metas. Para além desta situação, não é incomum que professores que solicitam licenças para estudos de pós-graduação, concomitantes com o horário de trabalho, tenham suas licenças indeferidas sob o argumento de carência de profissionais do ensino.

Muitos docentes são acusados de acomodação e de não atenderem aos apelos e ao esforço do governo, que buscaria uma educação de qualidade: "[...] cabe então ao professor, por conta própria e por livre decisão, fazer a sua parte: ser competente" (Del Pino; Vieira; Hypolito, 2009, p. 119). Reforça-se, desta forma, o foco no professor como principal (quando não único) responsável pelo sucesso ou insucesso de todo o sistema educacional.

Dito de outra maneira, não é difícil perceber que quando o professor busca se qualificar em função do seu trabalho é criticado, já que o deve fazer apenas fora do horário regular. E, se ele não busca, é taxado de acomodado. Mas o que se conclui é que o oposto da acomodação não é sinônimo da busca de continuação dos estudos, mas apenas de atender aos índices e rankings estabelecidos: nada voltado para a expansão da vida.

Na medida em que os professores queiram buscar trabalhar em função de objetivos diferentes daqueles estabelecidos por outros, desafiando as metas impostas ou deixando-as em segundo plano, eles podem enfrentar problemas, tais como o medo de serem considerados fracassados ou mesmo de enlouquecerem (Rolnik, 1999). Medo de não

Educação \& Realidade, Porto Alegre, v. 38, n. 3, p. 999-1018, jul./set. 2013. 1011 Disponível em: <http://www.ufrgs.br/edu_realidade> 
serem considerados competentes e eficientes: exigência de se alcançar o que é esperado, sob pena de sucumbir à culpa.

Cada vez mais os profissionais da educação têm sido estimulados a confiarem em suas "[...] habilidades e em seu esforço, sem esperar que a salvação venha do céu: culpar a si mesmos, a sua apatia ou preguiça, se tropeçarem ou quebrarem as pernas no caminho individual rumo à felicidade", à competência e à eficácia (Bauman, 2005, p. 52).

Os docentes se autocontrolam e modificam seus comportamentos em uma busca individual pelo alcance dos resultados. Porém, nessa busca incessante pelas metas, eles poderão desenvolver, caso não alcancem os resultados esperados, um intenso sentimento de culpa pelo fracasso pessoal e coletivo.

Dejours (1992, p. 102) já afirmava que os funcionários podem ser controlados a qualquer momento, sem sequer saber que este controle está sendo exercido, acabando por construir-se um autocontrole: "[...] ter medo de ser vigiado é vigiar-se a si mesmo". Para o autor, o medo e a ansiedade representam os meios pelos quais é possível se fazer respeitar os preceitos hierárquicos e os objetivos que se deseja atingir. Para Dejours (1992), com a culpa, a frustração alimenta a disciplina e a agressividade e isso se transforma em culpa, num círculo vicioso.

Também Nietzsche (1998, p. 51) se utilizava do exemplo do sacerdote ascético para ilustrar como as religiões mantinham o poder sobre as pessoas estimulando-as a sentirem-se culpadas e responsáveis por seus pecados. Ele alertava para o fato de que todo doente procura um culpado para sua doença e que a culpa é estimulada "[...] para o fim do autodisciplinamento, autovigilância, auto-superação", ou seja, para o controle.

Quantos professores são pressionados e se culpam quando não atingem as metas estabelecidas para (e não com) eles, assim como nas grandes corporações privadas? Porém, essas metas não dependem apenas do esforço destes profissionais, mas de seus estudantes, de estudantes de outras turmas e professores, e de toda a unidade escolar, bem como de inúmeros fatores de influência da vida de todos os envolvidos.

O controle se expande e novas subjetividades docentes vão sendo construídas: cobranças sobre si mesmo, autocontrole e culpa, combinados com cobranças e controle sobre o trabalho de colegas, alunos e todos os envolvidos.

É importante reparar que a culpabilização é função da subjetividade capitalista:

[...] muitas vezes acabamos correndo um grande risco de cair automaticamente numa espécie de buraco, que faz com que a gente comece a se indagar: 'afinal de contas quem sou eu? Será que sou uma merda?' É como se nosso próprio direito de existência desabasse. E aí se pensa que a melhor coisa que se tem a fazer é calar-se e interiorizar 
esses valores. Mas quem é que diz isso? Talvez não seja necessariamente o professor, ou o mestre explícito exterior, mas sim algo de nós mesmos, em nós mesmos e que nós mesmos reproduzimos (Guattari; Rolnik, 2007, p. 49).

A partir disso, não é difícil perceber que os sistemas de culpabilização funcionam como fator de inibição de tudo aquilo que foge do que é esperado pela lógica dominante. Por isso mesmo Daniel Lins (2004) afirma que a culpabilidade da existência se opõe a inocência do devir, do vir-a-ser: a razão não pode ser dissociada de uma ética do erro, da culpa.

É corrente o medo de não conseguir ser um professor-exemplo, um vencedor, um superador de metas. E cada vez mais, "[...] só existe lugar para 'super empregados', que devem ser 'super-homens': bonitos, felizes, altamente qualificados, que não cometem erros, enfim, perfeitos” (Castelhano, 2005, p. 16).

O professor-exemplo acima citado precisa investir todas as suas energias para que se atinjam todas as metas. Obviamente, ele nunca chega lá, já que lá é uma miragem, o terreno da perfeição. E quanto mais ele se frustra, corre atrás cada vez mais (Rolnik, 1997), desorientado, estressado, ansioso, perseguido, culpado, deprimido.

\section{Considerações}

A questão de buscar manter os docentes sob controle dentro do escopo de normas, atitudes e valores desejados por uma organização não parece muito diferente do que diversas religiões já fazem quanto à questão moral (Nietzsche, 1998). É notável a verificação contemporânea de elementos ligados àquilo que Foucault (2005) já apontava com relação à sociedade disciplinar e também do que Deleuze (1992) discorreu a respeito das sociedades de controle.

No caso da educação formal brasileira, a partir dos dados analisados dentro deste texto, é possível inferir que não se visualiza, em terra brasilis, uma transição completa de uma sociedade disciplinar para uma sociedade de controle, mas sim a construção de sociedades nas quais características de ambas coexistem e se reforçam mutuamente.

Também não é nova a discussão a respeito da educação formal como disciplinadora (Foucault, 2005) e como representante de instância de controle (Deleuze, 1992). Ademais, não seria nenhuma novidade afirmar que os professores continuam sendo, na maior parte dos casos, tratados pelo Estado como responsáveis pelo que esse considera sucesso ou fracasso da Educação.

Uma questão gritante que este estudo aponta é justamente a importação de técnicas e ferramentas da Administração privada, voltada exclusivamente para os valores capitalistas, para o mundo da Educação e, mais precisamente, para a própria remuneração dos professores.

Educação \& Realidade, Porto Alegre, v. 38, n. 3, p. 999-1018, jul./set. 2013. 
Dois aspectos merecem considerações e podem ser objetos, inclusive, de posteriores análises, mais detalhadas e profundas.

Em primeiro lugar, o sucesso e o fracasso da Educação formal, em nível fundamental, médio e universitário, estão ligados a resultados de estudantes em provas (Prova Brasil, IDEB, ENADE, entre outros) parametrizadas que desprezam diferenças regionais, bem como todas as demais influências envolvidas nos processos educacionais, igualando estudantes a notas e promovendo consequentes ranqueamentos que estimulam a competição desde a mais tenra idade.

Em segundo lugar, não obstante que os professores continuem sendo apontados por muitos como os responsáveis pelo sucesso/fracasso referido no parágrafo anterior, sua própria sobrevivência mais básica parece estar cada dia mais ameaçada. Não é novidade que os (pífios) salários da grande maioria dos docentes brasileiros representam, para muitos, a única fonte de renda e, portanto, de adquirir os meios necessários para a manutenção de condições mínimas de vida.

Entretanto, com o progressivo advento da remuneração variável por desempenho em diversos municípios ao redor do Brasil (e do mundo), os próprios rendimentos dos docentes passam a estar ameaçados, na medida em que cada vez mais são atrelados aos resultados obtidos por seus alunos, turmas, unidades escolares, regiões administrativas e Estados nas provas de avaliação.

A introjeção de um sentimento de culpa por parte dos docentes pode ser entendida como resultante de um poder disciplinar (Foucault, 2005) exercido por forças potencializadas pelas novas formas de gestão do trabalho docente, importadas da gestão de empresas privadas capitalistas. Os docentes se culpam por suas turmas não atingirem as metas, por não se dedicarem tanto quanto deveriam, por ficarem doentes e não poderem ir ao trabalho.

Simultaneamente, essa culpabilização não é apenas efeito, mas também causa e instrumento de controle (Deleuze, 1992), na medida em que ajuda a construir o autocontrole nos professores, fazendo com que possam vir a desenvolver comportamentos, atitudes e modos de sentir, viver e trabalhar centrados apenas nos valores desejados para que os objetivos estabelecidos sejam atingidos. Nesse sentido, a culpa pode fazer com que adoeçam por não atingirem metas que não ajudaram a estabelecer e que não dependem exclusivamente deles, além de fazer com que trabalhem mesmo doentes em muitos casos, com que busquem um aperfeiçoamento contínuo (em busca de uma perfeição que nunca chega e/ou da qualidade total), e até mesmo com que responsabilizem alunos e outros professores pelos prêmios perdidos.

Colegas que faltam, que adoecem e que não demonstram comprometimento total com as metas podem ser vistos de maneira negativa, por estarem prejudicando o trabalho e as metas da unidade escolar: existe a possibilidade de que a competição se (re)produza como valor 
estimulado, em detrimento da ajuda mútua, da solidariedade e da colaboração.

Vale a pena reparar que da mesma forma que o controle pode agir sobre si e sobre o colega docente, também pode se acirrar ainda mais sobre os estudantes. Estamos construindo uma Educação cujos objetivos são apenas numéricos. A medida da qualidade da Educação é a nota do aluno em provas e sua frequência escolar. Não obstante, a medida da qualidade dos docentes é tratada como sinônimo da nota de seus alunos.

Uma pergunta que atravessa: quais serão os conteúdos ministrados em sala quando a própria sobrevivência material mais básica depender exclusivamente de um resultado, de um índice? E essa dúvida leva à outra: que conteúdos são cobrados nas referidas avaliações? Ao menos na Prova Brasil, atualmente, cobra-se Português e Matemática. Nada relacionado à solidariedade, amor, colaboração, à construção de vidas e sociedades mais justas e humanas, centradas na expansão da vida em todas as suas formas.

Corre-se o enorme risco de que se tornem cada vez mais numerosos os exemplos de docentes que responsabilizam seus alunos pela perda do prêmio que poderiam receber. Mais que isso, corre-se o risco de que a ideia de educar se consolide, cada vez mais, apenas como sinônimo de treinamento e decoreba para provas parametrizadas e de fazer com que o aluno frequente a escola, já que também entram no cálculo do IDEB aspectos como a evasão escolar e a repetência, reforçando ainda mais o controle comportamental de estudantes.

Portanto, não é exagero considerar que a remuneração variável por desempenho ao mesmo tempo estimula e faz uso da culpabilização de professores para atingir seus objetivos. Ela é uma política de gestão que carrega os valores capitalistas com o intuito de fazer com que cada docente introjete o controle de si, de colegas e de alunos, por meio da ameaça de serem privados de melhores condições materiais de sobrevivência, já que a grande maioria recebe salários ridiculamente baixos pela importância da função social que desempenham. Função social esta que, ao menos em nosso entendimento, vai muito além de resultados expressos por notas em provas parametrizadas e homogeneizadas.

Como se sentem os professores dentro desta nova realidade que se constrói e da qual são parte fundamental? Que impactos estas mudanças estão trazendo para as suas vidas? Para o trabalho docente? Para a Educação? E para a sociedade de maneira mais ampla? Como é possível resistir e construir valores diferentes dos estimulados pela lógica capitalista dentro deste contexto? Ficam aqui interrogações para próximos e necessários estudos.

A questão consiste em saber se não há outras maneiras de ver e praticar as coisas, se não há meios de fabricar outras realidades, outros referenciais (Guattari; Rolnik, 2007). É importante que tudo isso esteja 
ligado a novas formas de ver, de sentir e de agir. Construção de novas sensibilidades e novos modos de viver e de se relacionar. Enxergar os outros como potenciais aliados e amigos parece uma condição fundamental para se buscar desconstruir a lógica competitiva que impõe a todos nós a visão de que estamos todos em competição permanente uns com os outros.

A mobilização coletiva, possível a partir desse mútuo conviver baseado em relações afetuosas, é uma grande oportunidade de se questionar as políticas impostas de cima para baixo e de construir outras, baseadas em valores mais humanos. Concordamos com Nietzsche (2004) quando ele aponta que não será possível vislumbrar uma elevação cultural e humana, enquanto a instituição escolar estiver a serviço da manutenção do sistema vigente. Uma escola que não leva o aluno a questionar a realidade e que pune o professor por fazê-lo não cumpre seu papel.

Recebido em 16 de abril de 2012 Aprovado em 06 de outubro de 2012

\section{Nota}

1 Conjunto de valores que postula que as posições dos indivíduos na sociedade devem ser consequência do mérito de cada um. Ou seja, do reconhecimento público da qualidade das realizações individuais (Barbosa, 1999).

\section{Referências}

ALVES, Giovanni. Trabalho e Subjetividade: o espírito do toyotismo na era do capitalismo manipulatório. São Paulo: Boitempo, 2011.

BALL, Stephen. Diretrizes Políticas Globais e Relações Políticas Locais em Educação. Currículo sem Fronteiras, online, v. 1, n. 2, p. 99-116, jul./dez. 2001.

BALL, Stephen. Performatividade, Privatização e o Pós-Estado de Bem-Estar. Educação e Sociedade, Campinas, v. 25, n. 89, p. 1105-1126, set./dez. 2004.

BARBOSA, Lívia. Igualdade e Meritocracia: a ética nas sociedades modernas. 2. ed. Rio de Janeiro: Editora FGV, 1999.

BAUMAN, Zygmunt. Vidas Desperdiçadas. Rio de Janeiro: Jorge Zahar Editor, 2005.

BRASIL. Ministério da Administração e Reforma do Estado. Câmara da Reforma do Estado. Plano Diretor da Reforma do Estado. Presidência da República. Brasília-DF, 1995. Disponível em: <http://www.planejamento.gov.br/noticia.as $\mathrm{p} ? \mathrm{p}=$ not $\& \operatorname{cod}=524 \& \mathrm{cat}=238 \& \mathrm{sec}=25>$. Acesso em: 10 jan. 2008.

BRASIL. Ministério da Educação. Plano de Desenvolvimento da Educação (PDE). 2007. Disponível em: http://www.mec.gov.br. Acesso: em 10 de jan, 2008. BRESSER PEREIRA, Luiz Carlos. A Reforma Gerencial do Estado de 1995. Revista de Administração Pública, Lisboa, v. 34, n. 4, p. 55-72, mar. 2000.

CASSETARI, Nathalia. Remuneração Variável para Professores: revisão de literatura e desdobramentos no estado de São Paulo. 2010. Dissertação (Mestrado

1016 Educação \& Realidade, Porto Alegre, v. 38, n. 3, p. 999-1018, jul./set. 2013. Disponível em: <http://www.ufrgs.br/edu_realidade> 
em Educação) - Faculdade de Educação, Universidade de São Paulo, São Paulo, 2010.

CASTELHANO, Laura Marques. O Medo do Desemprego e a(s) Nova(s) Organizações de Trabalho. Psicologia e Sociedade, Belo Horizonte, v. 17, n. 1, p. 14-20, jan./abr. 2005.

CODO, Wanderley (Org.). Educação: carinho e trabalho. Petrópolis: Vozes, 1999. COSTA, Aurea; NETO, Edgard; SOUZA, Gilberto. A Proletarização do Professor: neoliberalismo na educação. São Paulo: Editora Instituto José Luís e Rosa Sundermann, 2009.

DEJOURS, Christophe. A Loucura do Trabalho: estudo de psicopatologia do trabalho. 5 ed. São Paulo: Cortez - Oboré, 1992.

DEL PINO, Mauro Augusto Burkert; VIEIRA, Jarbas Santos; HYPOLITO, Álvaro Moreira. Controle e Intensificação do Trabalho Docente: câmeras, novo gerencialismo e práticas de governo. In: FIDALGO, Fernando; OLIVEIRA, Maria Auxiliadora M.; FIDALGO, Nara Luciene Rocha (Org.). A Intensificação do Trabalho Docente: tecnologias e produtividade. Campinas: Papirus, 2009. P. 113-133.

DELEUZE, Gilles. Conversações. Rio de Janeiro: Editora 34, 1992.

FORD, Henry. Os Princípios da Prosperidade. 2 ed. Rio de Janeiro: Livraria Freitas Bastos, 1964.

FOUCAULT, Michel. Ditos e Escritos I: problematização do sujeito: psicologia, psiquiatria e psicanálise. Rio de Janeiro: Editora Forense Universitária, 2002.

FOUCAULT, Michel. Vigiar e Punir: nascimento da prisão. 30. ed. Petrópolis: Vozes, 2005.

FOUCAULT, Michel. Nascimento da Biopolítica: curso dado no Collège de France (1977-1978). São Paulo: Martins Fontes, 2008.

GUATTARI, Félix; ROLNIK, Suely. Micropolítica: cartografias do desejo. 8. ed. Petrópolis: Vozes, 2007.

LARANJEIRA, Sonia M. Guimarães. Fordismo e pós-fordismo. In: CATTANI, Antonio David (Org.). Trabalho e Tecnologia: dicionário crítico. Petrópolis: Vozes; Porto Alegre: Editora da UFRGS, 1997. P. 89-93.

LAZZARATO, Maurizio. As Revoluções do Capitalismo. Rio de Janeiro: Civilização Brasileira, 2006.

LINS, Daniel. Juízo e Verdade em Deleuze. São Paulo: Annablume, 2004.

LYOTARD, Jean François. A Condição Pós-Moderna. 13. ed. Rio de Janeiro: José Olympio, 2011.

MELLO, Guiomar N. Cidadania e Competitividade: desafios educacionais do terceiro milênio. 3. ed. São Paulo: Cortez, 1994.

MOREIRA, Vera Susana Lassance. Dobras da Subjetividade: a remuneração variável como caso-pensamento do contemporâneo. Psico, Porto Alegre, v. 38, n. 1, p. 95-106, jan./abr. 2007.

MOTTA, Fernando Cláudio Prestes; VASCONCELOS, Izabella F. Gouvêia. Teoria Geral da Administração. 3. ed. São Paulo: Thomson Learning, 2006.

NARDI, Henrique Caetano. Ética, Trabalho e Subjetividade: trajetórias de vida no contexto das transformações do capitalismo contemporâneo. Porto Alegre: Editora da UFRGS, 2006.

NERI, Marcelo. As Metas Educacionais e o IDEB 2.0. Revista Conjuntura Econômica, São Paulo, v. 63, n. 1, p. 44-47, jan. 2009.

Educação \& Realidade, Porto Alegre, v. 38, n. 3, p. 999-1018, jul./set. 2013 
NIETZSCHE, Friedrich. Genealogia da Moral: uma polêmica. 5. ed. São Paulo: Companhia das Letras, 1998.

NIETZSCHE, Friedrich. Escritos sobre Educação. Rio de Janeiro: Ed. PUC-Rio; São Paulo: Loyola, 2004.

OHNO, Taichi. O Sistema Toyota de Produção: além da produção em larga escala. Porto Alegre: Bookman, 1997.

OLIVEIRA, Dalila Andrade. A Reestruturação do Trabalho Docente: precarização e flexibilização. Educação e Sociedade, Campinas, v. 25, n. 89, p. 1127-1144, set./dez. 2004.

RIO DE JANEIRO. Decreto-Lei no 30.860, de 01 de julho de 2009. Dispõe sobre os critérios de premiação a ser concedida aos servidores. Diário Oficial [do Município do Rio de Janeiro], Rio de Janeiro, n. 71, p. 04, 02 jul. 2009.

ROBBINS, Stephen Paul. Administração: mudanças e perspectivas. São Paulo: Saraiva, 2002.

RODRIGUES, Jean Douglas Zeferino. Implicações do Projeto "São Paulo faz Escola" no Trabalho de Professores do Ciclo I do Ensino Fundamental. Dissertação (Mestrado em Educação) - Faculdade de Ciências e Letras, Universidade Estadual Paulista, 2010

ROLNIK, Suely. Uma Insólita Viagem à Subjetividade. Fronteiras com a Ética e a Cultura. In: LINS, Daniel (Org.). Cultura e Subjetividade: saberes nômades. Campinas: Papirus, 1997. P. 25-34

ROLNIK, Suely. Novas Figuras do Caos: mutações da subjetividade contemporânea. In: SANTAELLA, Lucia; VIEIRA, Jorge Albuquerque (Org.). Caos e Ordem na Filosofia e nas Ciências. São Paulo: Face e Fapesp, 1999. P. 206-221.

ROLNIK, Suely. Cartografia Sentimental: transformações contemporâneas do desejo. Porto Alegre: Sulina; Editora da UFRGS, 2006.

TAYLOR, Frederick Winslow. Princípios da Administração Científica. São Paulo: Atlas, 1990

Simone Torres Evangelista é professora da Prefeitura Municipal do Rio de Janeiro. Licenciada em Pedagogia pela Universidade do Estado do Rio de Janeiro (UERJ). Mestre e Doutoranda em Educação pela Universidade Federal Fluminense (UFF). Bolsista do CNPq.

E-mail: sitorres.evangelista@gmail.com

Igor Vinicius Lima Valentim leciona no Departamento de Administração da Universidade Federal do Rio de Janeiro. Publicou Uma cartografia com a Economia Solidária: vivências em Portugal e Açores (Compassos Coletivos, 2013) e Residência Solidária UFRGS: vivência de universitários com o desenvolvimento de uma tecnologia social (Ed. da UFRGS, 2006). É membro do Centro de Investigação em Sociologia Econômica e das Organizações (SOCIUS).

E-mail:valentim@gmail.com 